Short Communication

\title{
Expression of somatostatin, dopamine, progesterone and growth hormone receptor mRNA in canine cortisol-secreting adrenocortical tumours
}

\author{
Miriam M.J. Kool, Sara Galac *, Noortje van der Helm, Catharina G. Spandauw, \\ Hans S. Kooistra, Jan A. Mol \\ Department of Clinical Sciences of Companion Animals, Faculty of Veterinary Medicine, Utrecht University, Yalelaan 108, 3584 CM Utrecht, The Netherlands
}

\section{A R T I C L E I N F O}

\section{Article history:}

Accepted 17 May 2015

\section{Keywords:}

Dog

Adrenal tumour

Hypercortisolism

Hormone receptors

\begin{abstract}
A B S T R A C T
Cortisol-secreting adrenocortical tumours (AT) in dogs are characterised by uncontrolled growth and excessive cortisol secretion. Dysregulated hormone receptor expression might be involved in tumour growth and hypersecretion of cortisol. The relative mRNA expression of growth hormone receptor, progesterone receptor, somatostatin receptors (SSTR1-3) and dopamine receptors $\left(D R D_{1-2}\right.$ and $\left.D R D_{5}\right)$ was evaluated in 36 canine ATs and 15 adrenal glands obtained from healthy dogs. Compared with normal adrenal tissue, $D R D_{2}$ mRNA expression was relatively lower in carcinomas, while SSTR1 mRNA expression was lower in both adenomas and carcinomas. Both of these features might contribute to loss of inhibition of tumour growth and upregulation of cortisol secretion. In canine ATs that had recurred within 30 months of surgical adrenalectomy, a marked increase in expression of $D R D_{1}$ mRNA was observed. Targeting of specific hormone receptors, expressed by ATs, might be exploited for therapy.
\end{abstract}

(c) 2015 Elsevier Ltd. All rights reserved.
Cortisol-secreting adrenocortical tumours (ATs) are relatively common in dogs and are characterised by uncontrolled growth and excessive cortisol secretion, although the molecular mechanisms that contribute to these features remain to be fully established (Galac et al., 2010b). Altered expression of particular hormone receptors could impact on tumour growth and cortisol secretion, which might provide an opportunity for targeted therapy. Increased expression of growth hormone receptor (GHR) and progesterone receptor (PR) has been observed in human cortisol-secreting ATs (Lin et al., 1997; de Cremoux et al., 2008), which might represent an autocrine PRGHR mechanism, similar to that seen in canine mammary carcinomas (Mol et al., 1995). Overexpression of somatostatin receptors (SSTR1-5) (Mariniello et al., 2011) and the presence of $\mathrm{D}_{2}$-like dopamine receptors $\left(\mathrm{DRD}_{2}\right.$ and $\left.\mathrm{DRD}_{4}\right)$ have also been reported in human ATs (Pivonello et al., 2004). These receptors exert anti-proliferative and anti-secretory effects through $\mathrm{G}$ protein-mediated inhibition of cAMP signalling (Neve et al., 2004; Theodoropoulou and Stalla, 2013). The aim of the present study was to evaluate mRNA expression of SSTRs, $D R s, G H R$ and $P R$ in canine cortisol-secreting ATs.

Adrenal tissue samples were obtained from 36 dogs affected with cortisol-secreting ATs that had undergone surgical adrenalectomy. The diagnosis of adrenocorticotropic hormone (ACTH)-independent

\footnotetext{
* Corresponding author. Tel.: +31 302539683.

E-mail address: S.Galac@uu.nl (S. Galac).
}

hypercortisolism, due to a cortisol-secreting AT, was made as described previously (Galac et al., 2010a). Following completion of diagnostic testing, informed owner consent was obtained for use of residual AT tissues for research purposes, as approved by the Local Ethics and Welfare Committee.

The age of the dogs at the time of surgery ranged from 2 to 13 years (mean 9 years). Seven dogs were crossbreeds and the other dogs were of a variety of different breeds. Eighteen of the dogs were male (eight castrated) and 18 female (12 neutered). As a control group, whole tissue explants from 15 healthy dogs were available from archived tissue from unrelated clinical research studies for which approval had been obtained from the Ethical Committee of Utrecht University.

Histopathological examination of tissue biopsies, undertaken by a single ECVP board-certified pathologist, confirmed the diagnosis of AT and allowed classification of the tumours as adenoma $(n=11)$ or carcinoma ( $n=25$ ) (Galac et al., 2010a). Clinical follow-up information was available for 15 dogs and in seven of these cases recurrence of hypercortisolism was confirmed by endocrine testing within 30 months of surgical adrenalectomy. The remaining eight dogs remained in remission for at least 30 months after surgery (Galac et al., 2010a).

Total RNA isolation and cDNA synthesis were performed as previously described (Galac et al., 2010a). Primers were designed to allow PCR amplification of GHR, PR, SSTR1-3, SSTR5, DRD,$D R D_{2}$ and $D R D_{5}$ (Table 1). Details of primer design, quantitative RT-PCR 
Table 1

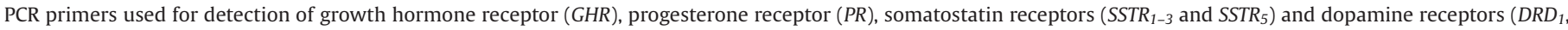
$D R D_{2}$ and $\left.D R D_{5}\right)$.

\begin{tabular}{|c|c|c|c|c|}
\hline Target & & Sequence $\left(5^{\prime}-3^{\prime}\right)$ & Annealing temperature & Product length (base pairs) \\
\hline GHR & $F w$ & GCGCATCCCAGAGTCTACA & $58^{\circ} \mathrm{C}$ & 133 \\
\hline NM_001003123.1 & $R v$ & ACCATGACGAACCCCATCT & & \\
\hline$P R$ & $F w$ & CAATGGAAGGGCAGCATAAC & $57^{\circ} \mathrm{C}$ & 102 \\
\hline NM_001003074.1 & $R v$ & CAGCACTTTCTAAGGCGACA & & \\
\hline SSTR1 & $F w$ & GTTCACCAGCATCTACTGTCTG & $66.3^{\circ} \mathrm{C}$ & 148 \\
\hline NM_001031816.1 & $R v$ & CAGAATGACCAGCAGCGAG & & \\
\hline SSTR2 & Fw & ACAGAGCCATACTATGACCTGACC & $60.5^{\circ} \mathrm{C}$ & 128 \\
\hline NM_001031817.1 & $R v$ & GTCTTCATCTTGGCATAGCGGAG & & \\
\hline SSTR3 & $F w$ & AGAACGCCCTGTCCTACTG & $60.7^{\circ} \mathrm{C}$ & 89 \\
\hline XM_005625695.1 & $R v$ & GAAGATGCTGGTGAACTGGT & & \\
\hline SSTR5 & $F w$ & CGGCACGCCAAGATGAAGACG & $65^{\circ} \mathrm{C}$ & 125 \\
\hline NM_001286852.1 & $R v$ & CCGAAGGGCCAGTAGGAGACG & & \\
\hline$D R D_{1}$ & $F w$ & CTCTGAACACCTCTACTATGG & $62.5^{\circ} \mathrm{C}$ & 145 \\
\hline XM_005619193.1 & $R v$ & AACCTGATGACAGCGG & & \\
\hline $\mathrm{DRD}_{2}$ & $F w$ & TAGGTGAGTGGAAATTCAGC & $58.6^{\circ} \mathrm{C}$ & 250 \\
\hline NM_001003110.1 & $R v$ & TTCTGGTCTGTGTTGTTGAG & & \\
\hline$D R D_{5}$ & $F w$ & CGTCTTCGTCTGGTTCG & $58^{\circ} \mathrm{C}$ & 149 \\
\hline XM_005618578.1 & $R v$ & CATTGCTGATGTTCACTGTC & & \\
\hline
\end{tabular}

$F w$, forward (sense) primer; $R v$, reverse (antisense) primer.

optimization and analysis of mRNA expression have been reported previously (Galac et al., 2010a). Ribosomal protein S5 (RPS5), ribosomal protein $S 19$ (RPS19), signal recognition particle receptor (SRPR) and beta-glucuronidase (GUSB) were used as reference genes. The relative expression of the reference genes revealed no significant differences between groups and reference gene expression was shown to be stable by analysis using GeNorm software. ${ }^{1}$ Target gene mRNA expression was deemed to be below the detection threshold if no specific amplicon could be detected after 40 cycles.

Statistical analyses were performed using IBM SPSS version 20. The Mann-Whitney $U$ test was used to compare relative mRNA expression values between adrenocortical adenomas or adrenocortical carcinomas vs. normal adrenal tissue. Additionally, mRNA expression profiles for ATs with or without recurrence of disease were compared. For the first comparison, Bonferroni correction was applied and $P<0.025$ was considered significant, while for the latter comparison, $P<0.05$ was considered significant.

For DRD5, SSTR3 and SSTR5, mRNA expression was below the detection threshold in a large proportion of samples, therefore these genes were excluded from further analysis. In all ATs and normal adrenals, GHR, PR, SSTR 1 and 2 and $D R D_{1}$ and $D_{2}$, mRNA was detected. Adrenocortical carcinomas demonstrated a significantly lower relative mRNA expression of $D R D_{2}(0.5$-fold, $P=0.002)$ and SSTR1 (0.4-fold, $P<0.001)$ when compared with normal adrenal gland tissue. In adrenocortical adenomas, only SSTR1 mRNA expression was significantly lower (0.3-fold, $P<0.001)$ (Fig. 1A). No significant differences were seen in the relative mRNA expression of GHR, $P R$, SSTR2 or $D R D_{1}$.

In adrenal carcinomas with recurrence of disease, a significantly greater expression of $D R D_{1}(4.2$-fold, $P=0.013)$ was detected (Fig. 1B). No significant differences in relative mRNA expression were detected for any of the other target genes. The results of the study indicate that for GHR, PR, SSTR1, SSTR2, DRD 1 and $D R D_{2}$, mRNA is present in normal adrenal tissue and ATs. In contrast to the situation in some human ATs, no hormone receptor overexpression was evident in any of the canine AT samples assessed. In adrenal carcinomas, relative mRNA expression of $D R D_{2}$ and SSTR1 was significantly lower, and the same held true for SSTR1 in adrenal adenomas. Decreased $D R D_{2}$ or SSTR1 mRNA expression may reflect an escape from the anti-secretory and anti-proliferative effects of

\footnotetext{
1 See: http://www.biogazelle.com/qbaseplus (accessed 16 May 2015).
}

somatostatin and dopamine signalling. The lack of changes in relative expression for $G H R, P R, D R D_{1}$ and $S S T R 2$ in the present study does not support a role for these receptors in the development of ACTH-independent hypercortisolism or uncontrolled AT growth.

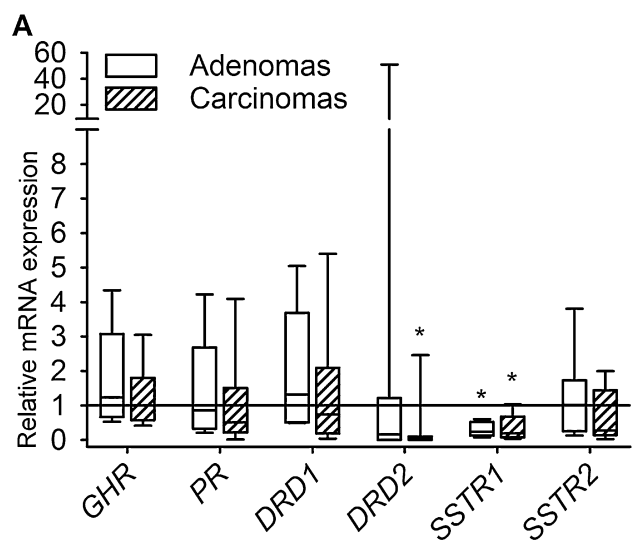

B

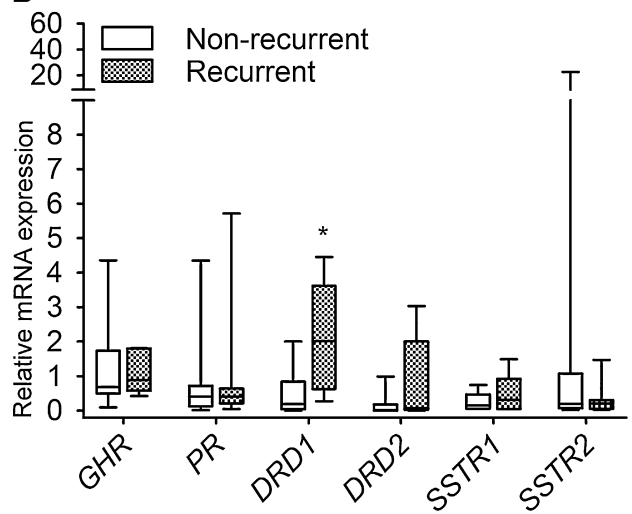

Fig. 1. Box-and-whisker plot showing relative mRNA expression of $G H$ receptor $(G H R)$, progesterone receptor $(P R)$, somatostatin receptors $\left(S S T R_{1-3}\right.$ and $\left.S S T R_{5}\right)$ and dopamine receptors $\left(D R D_{1}, D R D_{2}\right.$ and $\left.D R D_{5}\right)$ in canine ATs (11 adenomas and 25 carcinomas). (A) Relative mRNA expression in adenomas and carcinomas was calculated against values for normal adrenal glands $(n=15)$. (B) Relative mRNA expression in carcinomas from dogs demonstrating recurrence after surgical adrenalectomy, when compared with carcinomas from dogs that remained in remission. ${ }^{*} P<0.05$. 
Interestingly, $D R D_{1}$ expression was significantly greater in adrenal carcinomas from dogs that demonstrated recurrence of hypercortisolism. $\mathrm{DRD}_{1}$ is mainly associated with $\mathrm{G}$ protein stimulatory subunit alpha $\left(\mathrm{G}_{\mathrm{s} \alpha}\right)$-induced cAMP production (Neve et al., 2004). Aberrant cAMP signalling plays an important role in the development of human ACTH-independent hypercortisolism and adrenal tumourigenesis. We have previously demonstrated decreased expression of the ACTH-receptor in canine adrenal carcinomas, thus requiring alternative mechanisms for cAMPinduced cortisol secretion (Galac et al., 2010a). In approximately one third of cortisol-secreting ATs this appears to be related to the presence of activating Gs $\alpha$ mutations (Kool et al., 2013).

Enhanced DRD1 mRNA expression in adrenal carcinomas from dogs with recurrent disease may represent an alternative mechanism for induction of cAMP signalling, which is known to play a role in ATs. Additionally, detection of mRNAs encoding GHR, PR, SSTR1 and SSTR2 and $D R D_{1}$ and $D R D_{2}$ in all adrenal samples suggests the likely presence of these receptors in canine cortisol-secreting ATs, which might be amenable to therapeutic modulation.

\section{Conflict of interest statement}

None of the authors of this paper has a financial or personal relationship with other people or organisations that could inappropriately influence or bias the content of the paper. Pfizer Animal Health and Morris Animal Foundation played no role in the study design, or in the collection, analysis and interpretation of data, or in the decision to submit the manuscript for publication.

\section{Acknowledgements}

This study was supported by a Pfizer Animal Health-Morris Animal Foundation veterinary fellowship for advanced study (Grant number D09CA-913). The authors would like to thank Dr. S. Klarenbeek for performing the histopathological evaluation.

\section{References}

de Cremoux, P., Rosenberg, D., Goussard, J., Bremont-Weil, C., Tissier, F., Tran-Perennou, C., Groussin, L., Bertagna, X., Bertherat, J., Raffin-Sanson, M.L., 2008. Expression of progesterone and estradiol receptors in normal adrenal cortex, adrenocortical tumors, and primary pigmented nodular adrenocortical disease. EndocrineRelated Cancer 15, 465-474.

Galac, S., Kool, M.M., Naan, E.C., Daminet, S., Mol, J.A., Kooistra, H.S., 2010a. Expression of the ACTH receptor, steroidogenic acute regulatory protein, and steroidogenic enzymes in canine cortisol-secreting adrenocortical tumors. Domestic Animal Endocrinology 39, 259-267.

Galac, S., Reusch, C.E., Kooistra, H.S., Rijnberk, A., 2010b. Adrenals. In: Clinical Endocrinology of Dogs and Cats, Second Ed. Schlütersche, Hannover, pp. 93-154.

Kool, M.M., Galac, S., Spandauw, C.G., Kooistra, H.S., Mol, J.A., 2013. Activating mutations of GNAS in canine cortisol-secreting adrenocortical tumors. Journal of Veterinary Internal Medicine 27, 1486-1492.

Lin, C.J., Mendonca, B.B., Lucon, A.M., Guazzelli, I.C., Nicolau, W., Villares, S.M., 1997. Growth hormone receptor messenger ribonucleic acid in normal and pathologic human adrenocortical tissues - an analysis by quantitative polymerase chain reaction technique. The Journal of Clinical Endocrinology and Metabolism 82, 2671-2676

Mariniello, B., Finco, I., Sartorato, P., Patalano, A., Iacobone, M., Guzzardo, V., Fassina, A., Mantero, F., 2011. Somatostatin receptor expression in adrenocortical tumors and effect of a new somatostatin analog SOM230 on hormone secretion in vitro and in ex vivo adrenal cells. Journal of Endocrinological Investigation 34, e131-e138.

Mol, J.A., van Garderen, E., Selman, P.J., Wolfswinkel, J., Rijinberk, A., Rutteman, G.R., 1995. Growth hormone mRNA in mammary gland tumors of dogs and cats. The Journal of Clinical Investigation 95, 2028-2034.

Neve, K.A., Seamans, J.K., Trantham-Davidson, H., 2004. Dopamine receptor signaling. Journal of Receptor and Signal Transduction Research 24, 165-205.

Pivonello, R., Ferone, D., de Herder, W.W., de Krijger, R.R., Waaijers, M., Mooij, D.M., van Koetsveld, P.M., Barreca, A., De Caro, M.L., Lombardi, G., et al., 2004. Dopamine receptor expression and function in human normal adrenal gland and adrenal tumors. The Journal of Clinical Endocrinology and Metabolism 89, 4493-4502.

Theodoropoulou, M., Stalla, G.K., 2013. Somatostatin receptors: From signaling to clinical practice. Frontiers in Neuroendocrinology 34, 228-252. 